\title{
PHARMACIST PROFESSION STUDENT PERCEPTION ABOUT PHARMACIST ROLE IN PHARMACY, COMMUNITY HEALTH CENTER AND HOSPITAL
}

\author{
Kadek Nadia Martha Dewi ${ }^{1}$, Made Ary Sarasmita ${ }^{1,2}$, Luh Putu Febryana Larasanty ${ }^{1,2^{*}}$ \\ ${ }^{1}$ Pharmacy Study Program, Faculty of Mathematics and Natural Sciences, Udayana \\ University \\ ${ }^{2}$ Pharmacist Profession Study Program, Faculty of Mathematics and Natural Sciences, \\ Udayana University
}

Corresponding author email: febryana@unud.ac.id

\begin{abstract}
Background: Pharmacists play a role as a part of health services both at pharmacies, hospitals and community health centers. Pharmaceutical care was regulated in the Regulation of the Minister of Health of the Republic of Indonesia. In the internship, students of the Pharmacists program Faculty of Mathematics and Natural Sciences, Udayana University can see clearly how the implementation of the role of Pharmacists in the Pharmacy, Hospital and Community Health Center. Objective: This study aims to assess the perceptions (responses) of Pharmacist students on the role of Pharmacists in various pharmacy services. Methods: This study used a one-group posttest only design methods. The population of the study used all of the Pharmacist students who were internship at the Pharmacy, Community Health Center and Hospital. The research instrument used a closed-ended questionnaire about the perceptions of Pharmacist students on the role of Pharmacists in internship locations. Results: The results showed that the role of pharmacists in pharmacies and community health centers was greater in the field of clinical pharmacy services. While in hospitals, pharmacists have a greater role in the field of drug management. Conclusion: Students have a positive perception of the role of pharmacists. There were no significant differences in perceptions of Pharmacist students on the role of Pharmacists in the field of drug management and clinical pharmacy services ( $p>0.05)$.
\end{abstract}

Keywords: pharmacist, pharmaceutical care, perception, role, students

\section{INTRODUCTION}

Health is a healthy state that is assessed physical, mental, spiritual and social. Health provides the possibility for individuals to be able to live productively, both social and economic. In order to gain health status, it is necessary to have resources in the field of health, both funds, personnel, health supplies, pharmaceutical supplies and health facilities. Pharmacists are a part of human resources in the process of health care. Pharmacists have a role in providing pharmaceutical services related to the service of drugs and pharmaceutical supplies ${ }^{[1]}$. Pharmacists can work in health care facilities such as hospital, pharmacy, clinic and health center to be able to perform pharmaceutical services.

Pharmacy services by Pharmacists have been regulated by the Minister of Health Regulation No. 72 of 2016 for Hospitals, Number 73 of 2016 for Pharmacies and Number 74 of 2016 for Community Health Center. Based on the Minister of Health Regulation, pharmacy service standards by Pharmacists include the management of pharmaceutical 
preparations, medical devices and consumable medical materials and clinical pharmacy services. To be able to improve health services to the community, especially in the field of pharmacy services, the pharmacy service standards must be carried out starting with the education of future pharmacist ${ }^{[2,3,4]}$.

Pharmacist professional education is professional education taken after students graduate in Pharmacy undergraduate education. Based on competency standards set by the Indonesian Pharmacy Higher Education Association (APTFI), at the level of Pharmacist professional education, Pharmacy students should be exposed to various drug-related problems faced by patients/ the public in the hope of increasing pharmacist graduate competency ${ }^{[5]}$. Pharmacist professional education is designed by prioritizing Pharmacist Professional Work Practices (PPWP).

Pharmacist Professional Work Practices (PPWP) is practical activities for Pharmacy students in various places where Pharmacists can do pharmacy work. In this PPWP activity, students will be guided by the preceptor to practice directly. Thus it is expected to be a correlate between the theories obtained during lectures with the practice that will be implemented later after graduating from Pharmacist education. Pharmacist graduate is expected to be ready to carry out their professional roles in the community ${ }^{[6]}$. During PPWP activities, students can see the role of the Pharmacist in the practice of pharmacy services directly. This study aims to assess the perceptions (responses) of Pharmacy students on the role of Pharmacists in various pharmacy service practice places such as Pharmacies, Community Health Center and Hospitals. The benefits gained from this study are to know how much pharmacist students comprehend their future role as a pharmacist in the community.

\section{METHODS}

\section{Instrumental}

The research instrument used was a questionnaire with a closing statement with four levels of assessment, namely 1 for the assessment of strongly disagree, 2 for the assessment of disagree, 3 for the assessment of agreeing and 4 for the assessment of strongly agree. Statement in the questionnaire was developed based on the pharmaceutical service standards in each PPWP location (Pharmacy, Community Health Center and Hospital) and grouped into 2 parts, namely a statement on the role of Pharmacists in the management of pharmaceutical preparations, medical devices and consumable medical materials and a statement on the role of Pharmacists in clinical pharmacy services. Validation of the questionnaire uses a logical validity test $^{[7]}$.

\section{Study Design and Subjects}

This study used a one-group posttest only design research design ${ }^{[8,9]}$. The study population were all the pharmacist students of the Faculty of Mathematics and Natural Sciences, Udayana University, who were conducting PPWP in pharmacy, community health centers and hospital. Because of the limited number of research populations, no research sampling was taken. The research subjects took the entire study population who were willing to take part in the research by filling out the research instrument completely. The study was conducted in April - October 2018. The study was conducted after students completed PPWP activities.

\section{Data Analysis}

Data analysis was done by descriptive analysis in the form of an average of student responses to questionnaire statement. The average of student response to the questionnaire statement, then to be calculated into the percentage (\%) form and classifies to student perception based on 
table 1 . The statistical test used comparative non-parametric tests.

\section{RESULTS AND DISCUSSION}

The role of the Pharmacist in the health service process is an inseparable part.

Table 1. Classification of Perception

\begin{tabular}{ccc}
\hline No & Intervals & Classification \\
\hline 1. & $0-33.33 \%$ & Negative \\
\hline 2. & $>33.33 \%-66.67 \%$ & Neutral \\
\hline 3. & $>66.67 \%-100 \%$ & Positive \\
\hline
\end{tabular}

Pharmacists play a role in maintaining and in efforts to improve the quality of patient health ${ }^{[10]}$. The role of pharmacists in the field of health services ranging from ensuring the quality of pharmaceutical supplies to providing counselling services to patients, including monitoring drug use $\mathrm{e}^{[2-}$ ${ }^{4,10]}$. The process of professional education should be able to prepare graduated students to be able to practice professionally in the community. Good education plays an important role in increasing students' attitudes towards their primary role in carrying out the practice of their profession ${ }^{[11]}$.

In total 51 students took part in PPWP, but only 35 people filled out the research questionnaire at the Pharmacy, 33 people filled out the research questionnaire at the Community Health Center and 34 people filled out the research questionnaire at the Hospital. The percentage of responses from research subjects can be seen in table 2 .

Table 2. Percentage of Responses From Study Respondents

\begin{tabular}{clcc}
\hline No & \multicolumn{1}{c}{$\begin{array}{c}\text { PPWP } \\
\text { Place }\end{array}$} & $\begin{array}{c}\text { Number of } \\
\text { Respondents }\end{array}$ & $\begin{array}{c}(\%) \\
\text { Response }\end{array}$ \\
\hline 1. & Pharmacy & 35 & $68.63 \%$ \\
\hline 2. & $\begin{array}{l}\text { Community } \\
\text { Health } \\
\text { Center }\end{array}$ & 33 & $64.70 \%$ \\
\hline 3. & Hospital & 34 & $66.67 \%$ \\
\hline
\end{tabular}

The results showed that most students considered that Pharmacists had a role in carrying out pharmacy services both in Pharmacies, Community Health Center and Hospitals. In figure 1 it can be seen that the percentage of students who answer "agree" and strongly agree is much greater than those who answer strongly disagree and disagree.

Average of all responses show $70.95 \%$ of students agree that Pharmacists play a role in the process of drug managing cycles at the Pharmacy, $75.55 \%$ of students agree Pharmacists play a role in the process of managing drugs and others at the Hospital and $80.05 \%$ of students agree pharmacists play a role in the process of managing drugs and others at the health center. As for clinical pharmacy services, the results of the study showed $77.24 \%$ results, $73.90 \%$ and $81.44 \%$ respectively for the role of Pharmacists in Pharmacies, Hospitals and Health Centers. There is no significant difference between the results of students' perceptions of the role of Pharmacists in the field of drug management and clinical pharmacy services both in Pharmacies, Hospitals and Health Centers ( $p>0.05)$ as shown in table 3 .

Table 3. Categories of Pharmacist Student Perceptions of The Role of Pharmacists in Pharmacy, Community Health Center and Hospital

\begin{tabular}{|c|c|c|c|}
\hline No & PPWP Place & $\begin{array}{c}\text { Average } \\
\text { Student } \\
\text { Rating }\end{array}$ & $\begin{array}{c}\text { Perception } \\
\text { Category }\end{array}$ \\
\hline \multirow[t]{7}{*}{1.} & Pharmacy & & \\
\hline & - Role in drug & $70.95 \%$ & Positive \\
\hline & management & $77.24 \%$ & Positive \\
\hline & & & \\
\hline & pharmacy & & \\
\hline & services & & \\
\hline & \multicolumn{3}{|c|}{$\mathrm{p}$ value $=0.564$} \\
\hline \multirow[t]{7}{*}{2.} & Hospital & & \\
\hline & - Role in drug & $75.55 \%$ & Positive \\
\hline & management & $73.90 \%$ & Positive \\
\hline & - Role in clinical & & \\
\hline & pharmacy & & \\
\hline & services & & \\
\hline & \multicolumn{3}{|c|}{$\mathrm{p}$ value $=0.773$} \\
\hline \multirow[t]{7}{*}{3.} & Community & & \\
\hline & Health Center & $80.05 \%$ & Positive \\
\hline & $\begin{array}{l}\text { - Role in drug } \\
\text { management }\end{array}$ & $81.44 \%$ & Positive \\
\hline & - Role in & & \\
\hline & $\begin{array}{l}\text { clinical } \\
\text { pharmacy }\end{array}$ & & \\
\hline & services & & \\
\hline & \multicolumn{3}{|c|}{$\mathrm{p}$ value $=1.000$} \\
\hline
\end{tabular}




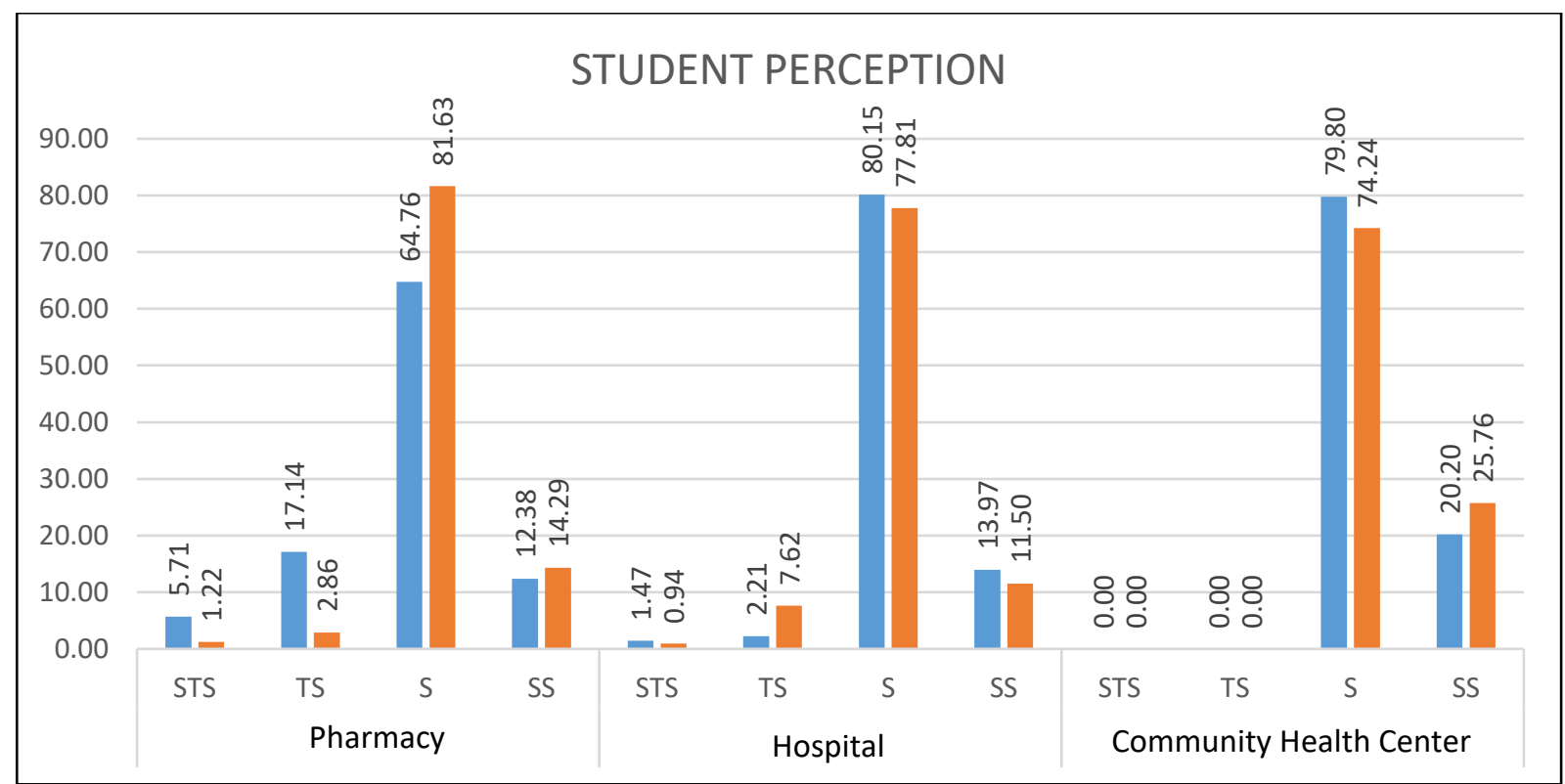

Information :

STS = strongly disagree; $\mathrm{TS}=$ disagree; $\mathrm{S}=$ agree; $\mathrm{SS}=$ very agree

$=$ pharmacist role in drug management cycles

$=$ phatmacist role in clinical pharmacy services

Figure 1. Student Perceptions of The Role of Pharmacists

Pharmacy students have a positive perception (average percentage of perception $>66.67 \%-100 \%$ ) of the role of Pharmacists in pharmacies, hospitals and health centers.

Pharmacist students consider that the Pharmacist's role is greater in the process of drug management than in clinical pharmacy services in hospitals. But the results of statistical tests show that the difference is not significant. Simpson (2017) discusses the role of Pharmacists in Hospitals, where Hospital Pharmacists have the main role as experts in the field of drug therapy, by providing a commitment to ensure the use of drugs that are safe and effective for patients. Based on student's perception, the role has been implemented, but the percentage is slightly smaller compared to the role of Pharmacists in managing drugs in hospitals. There was no statistically significant difference $(\mathrm{p}=0.773)$ on the assessment of student's perceptions in the implementation of the two roles of the Pharmacist in the Hospital ${ }^{[12]}$.

Pharmacy students consider that Pharmacists have a greater role in the field of clinical pharmacy services than in the management of pharmaceutical supplies, medical devices and consumable medical materials in Pharmacies and community health center. The results of this study are in line with the results of research obtained by Herman et al., in 2013 and Hanggara, et al., in 2017. The presence of pharmacists in the community health center has been shown to have a significant relationship with the performance of drug management in health centers $^{[13]}$. But Pharmacists still need to improve the quality of drug services such as prescription compounding, drug information services, and so on, which are part of clinical pharmacy services ${ }^{[14]}$.

The biggest difference in the percentage of student evaluations to the role of Pharmacist is in Pharmacy. The clinical role of pharmacists in pharmacies is something that the government and the professional association of pharmacists want to optimize. "No pharmacist no service" is a slogan echoed by the Indonesian Pharmacists Association ${ }^{[15]}$. The role of pharmacists in pharmacy in the field of clinical pharmacy services can be seen starting from self-medication services to the provision of home care in accordance 
with applicable laws and regulations ${ }^{[3,16]}$. The positive perception of students on the role of Pharmacists in health care facilities will have an influence in the form of an optimistic attitude for students to carry out their future careers as pharmacists who practice pharmaceutical services.

The results of this study can be used as one of the parameters to assess how far the implementation of pharmacy service practices from the perspective of Pharmacy students who carry out work practices in each health care place. This research also has several weaknesses. The first is a research method that only measures one assessment at the end of the PPWP period. So it cannot be compared whether students' perceptions were formed because of the PPWP process or indeed it was formed from the beginning. The second is the small number of respondents and the percentage of responses that did not reach $70 \%$. Further research needs to be done with better research methods and a larger number of respondents to get more concrete research results on the role of Pharmacists in health care facilities from various perspectives.

\section{CONCLUSION}

Pharmacist students of the Faculty of Mathematics and Natural Sciences Faculty of Udayana University have a positive perception of the role of Pharmacists both in pharmacy, community health centers and hospitals. Pharmacist student agreed that pharmacist has a role in drug management cycles and clinical pharmacy service at the pharmacy, community health centers and at hospitals setting.

\section{CONFLICTS OF INTEREST}

All authors declare that they have no known conflicts of interest.

\section{ACKNOWLEDGMENTS}

The researcher would like to thank the Faculty of Mathematics and Natural Sciences, Udayana University, which through the Research and Community
Service Institute has provided research grants through a HUPS scheme. Researchers also would like to thank all Pharmacist students who have been willing to take the time to participate in this study by completing a complete research questionnaire.

\section{REFERENCES}

1. Republic of Indonesia Government. Republic of Indonesia Law Number 36 Year 2009 regarding to Health. Jakarta: State Secretary of the Republic of Indonesia; 2009.

2. Minister of Health Republic of Indonesia $^{\mathrm{a}}$. Regulation of the Minister of Health of the Republic of Indonesia Number 72 Year 2016 regarding to Pharmaceutical Service Standards in Hospitals. Jakarta: The Indonesian Ministry of Health; 2016.

3. Minister of Health Republic of Indonesia ${ }^{\mathrm{b}}$. Regulation of the Minister of Health of the Republic of Indonesia Number 73 Year 2016 regarding to Pharmaceutical Service Standards in Pharmacies. Jakarta: The Indonesian Ministry of Health; 2016.

4. Minister of Health Republic of Indonesia $^{c}$. Regulation of the Minister of Health of the Republic of Indonesia Number 74 Year 2016 regarding to Pharmaceutical Service Standards in Community Health Center. Jakarta: The Indonesian Ministry of Health; 2016.

5. Indonesia Pharmacist Association. Indonesian Pharmacist Standard Competence. Jakarta: PP IAI; 2016.

6. Larasanty, LPF, Darayanti, NLKPW, Handayani, NKL, Puspita, LES, Putri, KTM, Suardiani, LAK. Preliminary study about pharmacist interns' expectation of their internship program, dalam prosiding International Conference on Pharmaceutical Research and Practice Conference. Yogyakarta: UII Press; 2018. pp 103107. 
7. de Yébenes Prous MJG., Salvanés FR., Ortells LC. Validation of questionnaires. Reumatol Clin. 2009; 5(4): 171-177.

8. University of Minnesota: Survey Design [homepage on the Internet] Minnesota : The University of Minnesota [cited 2019 January 27]. Available from https://cyfar.org/evaluation-designsposttest-only.

9. Kitchenham B., Pfleeger SL. Principles of survey research. Software Engineering Notes. 2002; 27(3): pp 2023.

10. Martodihardjo, S. Important, role of Pharmacist in health service [homepage on the Internet] Yogyakarta : Gadjah Mada University [cited 2019 January 27]. Available from: http://ugm.ac.id/id/berita/16180 2018.

11. Vestergard S., Norgaard LS., Traulsen JM., Kaae S. Pharmacy interns perception of their professional role. Am J Pharm Educ. 2017; 81(1): p 10.

12. Simpson SH. The Role we have as hospital pharmacist. The Canadian Journal of Hospital Pharmacy. 2017; 70(1): pp 3-4.

13. Herman MJ., Supardi S., Yuniar Y. Relationship between number of pharmacy staff with community health center characteristic and pharmaceutical service at community health center. Buletin Penelitian Sistem Kesehatan. 2013; 16(1): pp 88-98.

14. Hanggara RSL., Gibran NC., Kusuma AM, Galistiani GF. Impact of Pharmacist existence to the pharmaceutical service quality in the community health center in Banyumas region. Jurnal Kefarmasian Indonesia. 2017; 7(1): pp 67-76.

15. Rachmandani, Aulia, A., Sampurno. Role of Indonesian Pharmacist Association in the efforts to implement pharmaceutical service standards in
Pharmacy in the Special Region of Yogyakarta (Thesis). D.I. Yogyakarta: UGM; 2010.

16. World Health Organization. The Role of the pharmacist in health care system: community pharmacy. Japan: WHO; 1994. 